\title{
Gambling treatment options: a roll of the dice
}

$\mathrm{P}$ eople end up in Mike Lynch's office for many reasons. Some have money problems. Others are suffering mood swings, or are neglecting their jobs and families. In rare cases, police send people arrested for theft Lynch's way. Their stories vary, but Lynch's clients all have 2 things in common: they're addicted to gambling, and they want to get better.

"By the time they get to a bricksand-mortar facility, people are pretty motivated," says Lynch, an addictions counsellor with the Alberta Alcohol and Drug Abuse Commission.

Across Canada and around the world, people like Lynch are busier than ever. Gambling has exploded in popularity in recent years, and the treatment field has been in a perpetual state of catch-up. Canadian provinces devote millions to problem gambling research, treatment and awareness prevention.

Ontario invests the most (\$36 million in fiscal year 2006/07) with Quebec coming second (\$21 million). In total, at least $\$ 80$ million was spent across the country in fiscal year 2006/07 to address problem gambling.

That translates into just over $1 \%$ of the $\$ 6.8$ billion that provincial governments netted from gambling in fiscal year 2006/07 (CMAJ 2008:179[1]:21-2).

Since the early 1980s, the psychiatric profession has considered gambling addiction a mental disorder. Researchers have explored many treatments but are far from reaching a consensus on what works best. Some concentrate on pharmaceutical solutions, others on psychosocial therapies. A few addiction experts aren't optimistic that any form of active treatment will ever boast success rates much higher than the rate at which addicts recover on their own.

The road to recovery from gambling addiction in Canada often begins with a telephone call. Every province runs a problem gambling helpline, most open 24 hours a day. Callers are often directed to Gamblers Anonymous, a 12step recovery program, or to outpatient treatment facilities.

Outpatient programs help addicts understand their problem and teach them practical steps to avoid relapse.
Lynch, who works in Edmonton, Alberta, stresses 3 things to participants in his counselling programs: limit access to cash, get honest with loved ones and find a support group.

"There just seems to be some comfort in hanging out with other people who are going through the same issue," says Lynch. "It lowers depression and increases optimism."

Several provinces - including Ontario, Manitoba and Quebec - have in recent years created residential treatment programs. Ontario leads in this area, with programs in Windsor, Thunder Bay and Toronto. "People just didn't have an intensive enough program to overcome their problems," says Nick Rupcich, manager of Windsor Regional Hospital Problem Gambling Services. "Now we have a full continuum of care in the province."
Problem gamblers admitted to Windsor's 6-bed residential facility learn how to reduce stress, recognize irrational thinking and manage anger. They discuss the effects gambling has on families. They also attend morning and evening group therapy sessions and, once a week, an art therapy class.

Follow-up data collected from former patients indicates good outcomes, says Rupcich, who hopes to expand the 3 -year-old residential program. "We are booking beds 3 months in advance. Our wait time is increasing slightly over time and we don't want that to get too long."

Those with less severe gambling problems may not need residential or outpatient therapy. David Hodgins, an addiction researcher and professor of clinical psychology at the University of Calgary, claims that a common pathway to recovery for many addicts is to go it

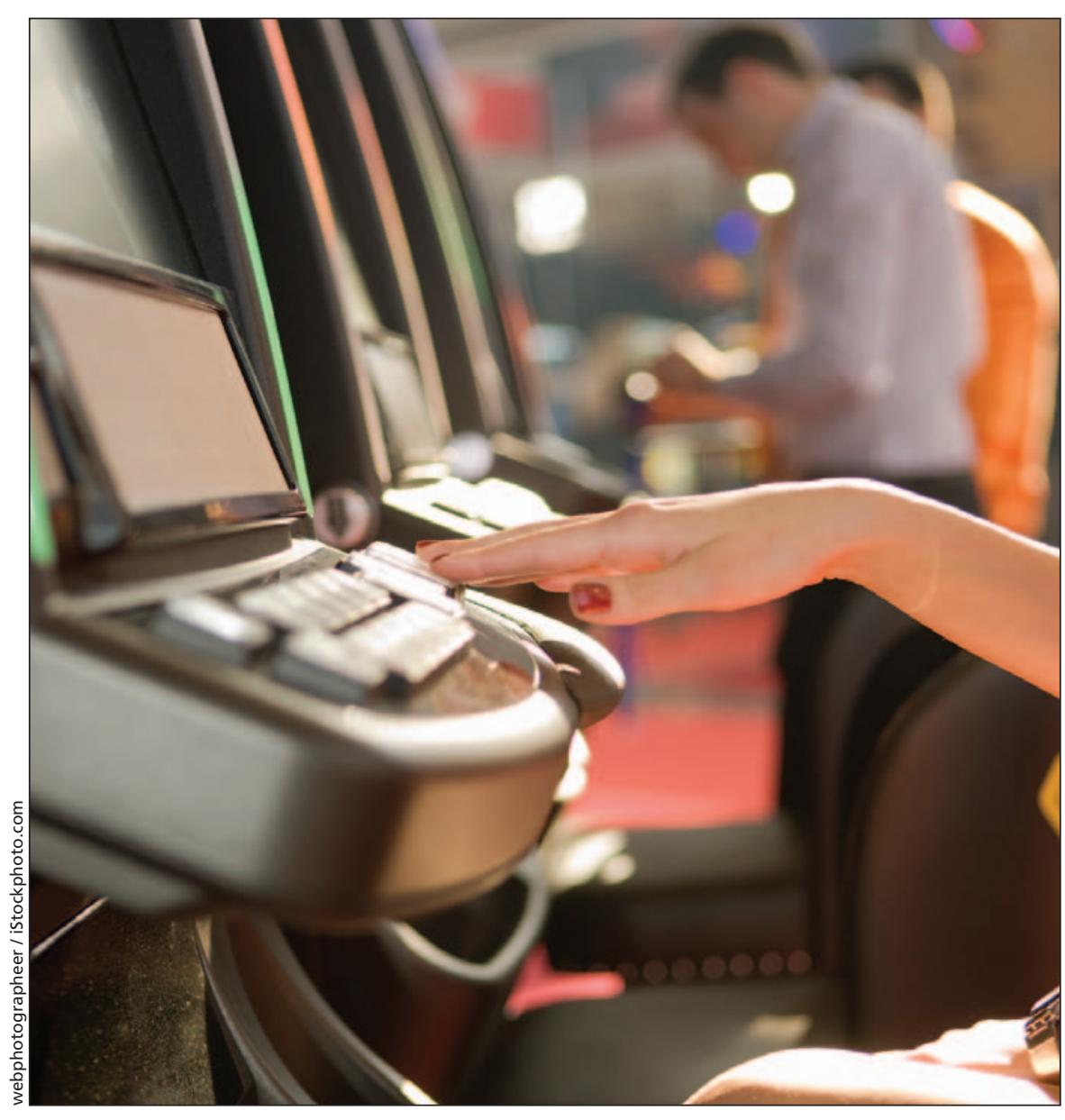

Many people recover from their gambling addiction without the aid of treatment, although they typically use processes similar to those used by people who receive therapy. 
alone. When he compared former gamblers who recovered naturally with those who recovered after treatment, he discovered that the processes that members from each group undertook to get better were similar (Addiction 2000;95 [5]:777-89).

"It may be that the recovery processes are the same but people need different amounts of support and information to engage those processes," says Hodgins.

Only $20 \%$ of people who chose selftreatment did so because there were no options. The vast majority opted for self-treament, for reasons ranging from embarrassment to fear of being stigmatized. Hodgins has found that self-help workbooks and brief motivational interviews can help such people reduce the severity of their gambling habits or, in some cases, stop gambling altogether without formal treatment ( $J$ Consult Clin Psychol 2001;69[1];50-7).

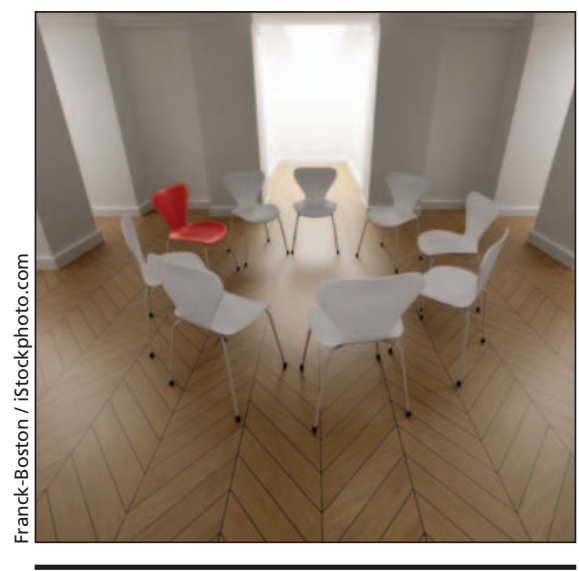

Group therapy, and in at least 1 case art therapy, lies at the core of therapeutic solutions offered by residential gambling treatment programs.

Whatever recovery path they choose, about $90 \%$ of problem gamblers relapse, a slightly higher rate than for other types of addicts. This doesn't mean recovery is near impossible to achieve, says Hodgins, but indicates that addicts often make several attempts before they succeed. Some addicts relapse because their personalities are ill-suited for the long, disciplined process required to pay off gambling-acquired debts.

"When you recover from an alcohol problem, your life is a mess at the point of recovery but you can put it together pretty quickly. Gamblers face all of those immediate messy aspects of life plus are going to be dealing with debt for many years, if not the rest of their lives."

One way recovering problem gamblers can blunt urges to visit casinos comes in pill form. Research indicates that lithium shows promise in reducing gambling impulses (Am J Psychiatry 2005;162:137-45).

Dr. Jon Grant, a professor of psychiatry at the University of Minnesota, has tested the opioid antagonist nalmefene to treat problem gambling. He found that $59 \%$ of the 270 gamblers who participated in his study improved greatly, compared to $34 \%$ of those who received placebos (Am J Psychiatry 2006;163:303-12).

"It will not stop people from gambling. A more accurate way to describe it would be that medication can reduce the desire to gamble and may help improve one's control over their behaviour," says Grant. "But they are not magic pills that people take and, even if they don't want to, they suddenly stop gambling and their lives are perfect again."

Grant has also found that the amino acid $N$-acetyl cysteine can manipulate the reward-seeking system of an addict's brain to inhibit gambling urges (Biol Psychiatry 2007;62[6];652-7).

However, combining behavioural therapy and medication may be the most effective means to treat gambling addiction, says Grant, though research may yet uncover superior pathways to recovery.

"As we learn more about addiction in general, we'll be able to explore other options so that we have multiple options to any one person."

Some addiction researchers, however, believe it's time to retire the disease model of addiction. Bruce Alexander, a psychology professor at Simon Fraser University and author of the forthcoming book The Globalization of Addiction, claims nothing short of major societal change will solve the problem of addiction.

"We live in a fragmented society. Kids and grown-ups don't get the emotional or psychological support they need from society so they compensate by falling into these addictive worlds," says Alexander.

Though not opposed to treatment,
Alexander claims it is of limited value and likely always will be. Addictions stem from problems with society, not individuals, he says, and therefore cannot be fixed by altering behaviour or brain chemistry.

"We're not going to treat our way out of this problem anymore than we were able to prohibit our way out of this problem or pray our way out of this problem," says Alexander. "Gambling is just like anything else that people do to fill that inner void that is a consequence of this society we've constructed." - Roger Collier, CMAJ

DOI:10.1503/cmaj.080959

\section{Briefly}

The 15\% ruling: Taser International Inc. suffered its first product liability suit loss in roughly 70 instances after a California district court ruled that it was $15 \%$ responsible in the death of a 40-year-old drug suspect who died after receiving simultaneous shots from 3 tasers used by police officers. The jury awarded US\$1.02 million in compensatory damages, as well as US\$5.2 million in punitive damages, for Taser International's failure to inform police that extended exposure to electric shock from the device could lead to cardiac arrest. The company said it plans to appeal the decision.

Organ removal ambulance: In a bid to boost organ supply, New York City, New York, says it will deploy a special ambulance later this year to collect the bodies of people who die from heart attacks, accidents and other emergencies. Organizers say that as many as 35000 additional transplants nationwide could be performed annually as a result of the initiative, which is funded under the rubric of a US $\$ 1.5$ million, 3-year grant from the federal Health Resources and Services Administration. The organ-recovery ambulance would be prohibited from arriving at a scene until 5 minutes after paramedics have made a formal declaration of death. - Wayne Kondro, CMAJ

DOI:10.1503/cmaj.080914 